\title{
ANÁLISE DO TUTOR MEDIADOR A LUZ DOS REFERENCIAIS DE QUALIDADE EM EAD
}

Willer Carlos de Oliveira ${ }^{1}$

OLIVEIRA, W. C. de. Análise do tutor mediador a luz dos referenciais de qualidade em EAD. EDUCERE - Revista da Educação, Umuarama, v. 20, n. 2, p. 301-336, jul./dez. 2020.

RESUMO: Na grande maioria dos discursos acerca da EaD, uma ampla diversidade de termos é apresentada e utilizada para referir-se ao indivíduo que faz a mediação. Entre os vários envolvidos no processo de ensinoaprendizagem da EaD, temos a figura do "tutor mediador", que emerge de formas múltiplas. Embora os estudos apresentem um vasto material e informações acerca do tutor mediador, essa pesquisa aborda a sua especificidade, a sua capacitação necessária, indicando a necessidade de uma reflexão mais profunda sobre a atuação do tutor mediador, segundo a sua própria perspectiva. Esta pesquisa teve como objetivo geral investigar, numa Universidade privada, o trabalho que o tutor mediador desenvolve, segundo a sua própria ótica, com foco, em particular, na relação entre a atuação do tutor e as questões da qualidade em EaD. O trabalho visou responder as seguintes questões de estudo: Qual a importância do tutor no processo ensino-aprendizagem na modalidade à distância? Qual a importância dos referenciais de qualidade para a educação superior a distância? Foi constado que se tutor é uma atividade bem mais complexa do que se pode relacionar. A exploração dos recursos de aprendizagem, a divulgação eficiente de informações essenciais, a administração, a observação, o acompanhamento, a reflexão, o esclarecimento, o apoio motivacional e a avaliação são aspectos fundamentais do trabalho do tutor mediador, podendo estabelecer que esse profissional na realidade é um professor e, portanto, um ser central à aprendizagem e que os referenciais de qualidade são a base de toda EaD.

DOI: 10.25110/educere.v20i2.2020.7669

${ }^{1}$ Graduado em História pela FAFIPA; e Ciências Contábeis pela UNESPAR. Especialista em Filosofia, Sociologia e Ensino Religioso pela Faculdade de Ensino Superior Dom Bosco; Métodos e Técnicas de Ensino - Tópicos Especiais de Metodologia de Ensino de Ciências Sociais pela UTFPR; Educação a Distância pela UNOPAR; Consultoria Empresarial pela Unipar, e Auditoria e Perícia Contábil FAVENI. Mestrando em Desenvolvimento Rural Sustentável pela UNIOESTE. 
PALAVRAS-CHAVE: Tutor; Qualidade; Educação a Distância.

\title{
ANALYSIS OF THE MEDIATING TUTOR IN THE LIGHT OF QUALITY REFERENCES IN DISTANCE LEARNING
}

\begin{abstract}
In most of the Distance Learning discourses, a wide range of terms is presented and used to refer to the individual who acts as a mediator. Among the many roles involved in the teaching-learning process within distance learning, there is the figure of the "mediating tutor", who emerges in multiple ways. Although the studies present a vast material and information about the mediating tutor, this paper addresses its specificity, its necessary training, indicating the need for a deeper reflection on the role of the mediating tutor, from his/her own perspective. This research aimed at investigating the work developed by the mediating tutor at a private university according to his own perspective, focusing especially on the relationship between the tutor's performance and the quality issues in distance learning. The work aimed at answering the following questions: What is the importance of the tutor in the teaching-learning process in the distance learning modality? How important are quality benchmarks for distance learning in higher education? It has been found that tutoring is a far more complex activity than previously thought. The exploitation of learning resources, the efficient dissemination of essential information, the administration, observation, monitoring, reflection, clarification, motivational support, and assessment are fundamental aspects of the mediator's work. It can be said that the mediator is in fact a teacher and therefore, a central player in learning. Thus, quality benchmarks are the basis of all distance learning education.
\end{abstract}

KEYWORDS: Tutor; Quality; Distance Learning.

\section{ANÁLISIS DEL TUTOR MEDIADOR A LA LUZ DE LOS REFERENCIALES DE CALIDAD EN EDUCACIÓN A DISTANCIA - EaD}

RESUMEN: En la gran mayoría de los discursos de EaD, se presenta una amplia gama de términos para referirse al individuo que hace la mediación. Entre los muchos involucrados en el proceso de enseñanza-aprendizaje de 
educación a distancia, tenemos la figura del "tutor mediador", que emerge de múltiples maneras. Aunque los estudios presentan un vasto material e informaciones sobre el tutor mediador, esta investigación aborda su especificidad, su capacitación necesaria, lo que indica la necesidad de una reflexión más profunda sobre el papel del tutor mediador, desde su propia perspectiva. Esta investigación tuvo como objetivo general investigar, en una Universidad privada, el trabajo que desarrolla el tutor mediador, según su propia perspectiva, centrándose en particular en la relación entre la actuación del tutor y los problemas de calidad en EaD. El trabajo ha buscado responder las siguientes preguntas de estudio: ¿Cuál es la importancia del tutor en el proceso de enseñanza-aprendizaje en la modalidad a distancia? ¿Cuál la importancia de los referenciales de calidad para la educación superior a distancia? Se ha encontrado que la tutoría es una actividad mucho más compleja de lo que puede relacionarse. La explotación de los recursos de aprendizaje, la difusión eficiente de informaciones esenciales, la administración, observación, monitoreo, reflexión, aclaración, apoyo motivacional y la evaluación son aspectos fundamentales del trabajo del mediador, pudiendo establecer que ese profesional en realidad es un profesor y, por lo tanto, un ser central al aprendizaje y que los referenciales de calidad son el cimiento de toda Educación a Distancia.

PALABRAS CLAVE: Tutor; Calidad; Educación a Distancia.

\section{INTRODUÇÃO}

No início do século XXI, percebemos um grande avanço tecnológico, especificamente nas áreas da informação e da comunicação, que vem repercutindo no modo de vida dos indivíduos, nos hábitos diários, nos relacionamentos e na forma de construir o conhecimento, fator este nos proporciona inúmeras transformações ideológicas, políticas, econômicas, sociais, estruturais, culturais e educacionais.

As tecnologias passaram a modificar vários aspectos do dia a dia e dos costumes do ser humano. Um grande exemplo é a informática e, com ela, a internet que se expandem e transformam as situações cotidianas, trazendo novas maneiras de realizar antigas ações, exigindo novos aprendizados, e o desenvolvimento de novos conceitos, enfim, vem reestruturando as relações. 
Uma ação importante da sociedade, na qual se observa a influência das tecnologias, é o uso da informática e da internet é na área da educação, principalmente a educação de nível superior. No dia a dia das vivências educacionais nas universidades e faculdades, o uso da informática e da internet já é expressivo, tanto por parte dos professores, quanto dos alunos.

Com o uso das tecnologias, a educação observa a necessidade de interagir com este "mundo" e com isso surge o novo modelo da educação a distância, que vem para vencer as demandas educacionais cada vez maiores da população, levando em conta a existência de limitações educacionais e vários outros fatores. No Brasil, a Educação a Distância foi regulamentada pela Lei de Diretrizes e Bases da Educação Nacional (LDB), $n^{\circ}$. 9.394, em 20 de dezembro de 1996. O Decreto $n^{\circ}$. 5.622, foi proposto em 2005 visando reformular e atualizar a legislação, definindo a educação a distância como uma modalidade educacional, cuja mediação didático-pedagógica se dá pela utilização de meios e tecnologias de informação e comunicação, levando em conta que os sujeitos encontramse em lugares e tempos diversos.

Com o passar dos anos e o aprimoramento das tecnologias, a educação a distância, tem sido foco das atenções de diversos segmentos da sociedade, sendo utilizada como mecanismo tanto de formação como de atualização profissional. No entanto, a EaD que pode ser considerada nova na realidade brasileira, apresenta-se como um novo desafio a ser enfrentado no sistema educacional. Surge a necessidade de se adaptar ao novo modelo de mercado e também aos efeitos do impacto da globalização na política educacional.

O ensino a distância torna-se cada vez mais praticado por muitas pessoas e começa a fazer parte da rotina dos brasileiros por diversos fatores. Esta modalidade surgiu no Brasil no século XIX com cursos profissionalizantes feitos por meio de correspondências e assim perdurou durante muitos anos, até chegar aos dias atuais. Existem vários fatores que levam alguns estudantes a optarem por essa modalidade, como, por exemplo, a autonomia de estudo, estudar onde desejar, necessidade de atualização de conhecimento e também baixo custo.

O termo "a distância" no leva a pensar em distância geográfica e isolamento. Logo, está aí o ponto chave desta modalidade que é superar 
qualquer distância, aproximar, interagir e para isso utiliza dos meios tecnológicos e de pessoas. Apesar dos envolvidos nesse processo sempre estarem atrás das telas, estão em boa parte do tempo, comprometidos no ato de orientar da melhor forma possível durante o desenrolar do processo.

A modalidade $\mathrm{EaD}$, propõe um rompimento da relação corpo a corpo entre alunos e professores, levando a crer que pode existir relações de ensino aprendizagem sem a necessidade de haver um grupo homogêneo de alunos que convivem em um mesmo espaço e tempo. A partir destas rupturas o aluno é levado a decidir sobre seu processo formativo de forma autônoma e independente. No entanto, é por trás desta autonomia que se encontra o tutor mediador, um orientador, considerado um novo tipo de educador que sugere novos caminhos, fomenta pensamentos e conduz de forma gradativa, a interação entre os conteúdos e as práticas, induzindo o aluno a criar e repensar conceitos.

A partir da perspectiva de pensamento sobre o tutor mediador, ele é visto como o orientador do aluno nesse sistema de ensino e a sua principal função é de acompanhar a vida acadêmica dos estudantes, apontar os caminhos e formar parcerias para resolver os problemas e atividades propostas. A sua ação está em facilitar o conhecimento, e por essa ação deve estar inteiramente consciente e integrado quanto aos conteúdos, metodologias, matérias, atividades, sobretudo, em qual contexto seu aluno está inserido, sua realidade, suas limitações, principalmente seu potencial.

Este trabalho pretende, a partir de pesquisas teóricas, ressaltar a importância do tutor mediador na $\mathrm{EaD}$, reforçando quais são as funções. Por isso, levantamos a seguinte questão: Qual a importância do tutor no processo ensino-aprendizagem na modalidade a distância? Qual a importância dos referenciais de qualidade para a educação superior a distância?

\section{REVISÃO BIBLIOGRÁFICA}

\subsection{A Educação a Distância: Formação, Docente, Tutor e Referenciais de Qualidade}

A prática da tutoria na modalidade $\mathrm{EaD}$, tem a função de caracterizar a Educação a Distância, como educação mediada por 
tecnologias de informação e comunicação, por processos didáticopedagógicos. Logo, é certo pensar que essa mediação é realizada pelos sujeitos envolvidos, e entre eles encontra-se o tutor.

A EaD tem uma relação educativa mediada e mediatizada entre o professor, autor de conteúdo/ tutor/ especialista e estudantes. O tutor é responsável por fazer a ponte entre o aluno, professor e instituição. Em um cenário, repleto de situações, possibilidades e espaços diferentes do ensino presencial, encontramos a modalidade $\mathrm{EaD}$, além de uma sala de aula, como professor e estudantes que de forma separada no tempo e no espaço, podem estudar e garantir qualidade na formação.

Podemos caracterizar então, que, uma das mais importantes características de uma educação mediada por tecnologias de informação e comunicação é, sem dúvida, uma organização de um sistema de apoio ao aluno, onde um sistema tutorial de apoio presencial e a distância passa a ser representantes e/ou elo do aluno com sua instituição, seja para acompanhar, informar ou diretamente atuar no processo de ensino e aprendizagem.

É importante que o tutor tenha sua formação acadêmica e experiência em educação, sendo imprescindível que tenha experiência no ensino presencial, assim compreende a diversidade dos sujeitos e a complexidade do processo ensino aprendizagem.

A EaD não se limita a um processo informativo, um método por exemplo, o que garante a qualidade de um processo pedagógico é: concepção, conhecimento específico e organização didática metodológica, assim com competência para organizar pesquisas criativas e situações provocativas, devem estar presentes no processo, abordando experiências, orientando leituras, pesquisas, compartilhando com os alunos estratégias de ensino, orientando na escolha de materiais para pesquisa e construindo conhecimento. É um processo educacional que acontece, principalmente com professores e alunos fisicamente separados, mas que se comunicam por meio das tecnologias de informação e comunicação.

Os Referenciais de Qualidade para a Educação Superior a Distância (MEC, 2007 p. 21) consideraram que os professores veem suas funções se expandirem em programas a distância, o que requer que sejam altamente qualificados. Por sua vez, neste contexto caracteriza-se o tutor como um agente fundamental nos processos de aprendizagem, avaliação 
e interação. Neste documento fica estabelecido que:

O tutor deve ser compreendido como um dos sujeitos que participa ativamente da prática pedagógica. Suas atividades desenvolvidas a distância e/ou presencialmente devem contribuir para o desenvolvimento dos processos de ensino e de aprendizagem e para o acompanhamento e avaliação do projeto pedagógico.

Contudo percebemos que o tutor mediador se torna responsável pela mediação e acompanhamento do aluno, oferecendo todo o suporte necessário em relação ao conteúdo da disciplina ou do curso.

Segundo Niskier (1999), as ações do tutor mediador na educação a distância, se caracteriza ao ato de comentar os trabalhos realizados pelos alunos; corrigir avaliações; dar suporte pedagógico durante o curso; organizar os estudos; atualizar o aluno e principalmente fazer a ponte entre o aluno e a instituição, servindo como um facilitador e mediador da aprendizagem, motivando e orientando os alunos e acima de tudo um avaliador.

Conforme Belloni (2001), o tutor deve estar envolvido nas três dimensões dos saberes docentes que são: Pedagógica, Tecnológica e a Didática.

Podendo-se destacar como características importantes para um tutor mediador, a capacidade de estabelecer relações de empatia com os acadêmicos e o domínio das suas ferramentas de trabalho.

\subsection{A Modalidade de Educação a Distância - Ead}

Esta modalidade de educação é uma modalidade alternativa, capaz de superar limites de tempo e espaço, adequada e desejada para atender as fortes demandas educacionais forçadas pela nova ordem mundial. (Belloni, 2006).

Uma das características mais comentadas desta modalidade é a separação espacial e temporal do docente e discente, ligados pelo uso de instrumentos, materiais e tecnologia criados para realizar a mediação e viabilizar o processo ensino-aprendizagem.

Peters (2004) caracteriza a EaD como sendo uma modalidade 
de educação com objetivos e métodos diferentes, por não haver uma interação direta entre docentes e discente, ocorrendo apenas por meio de artefatos tecnológicos, o processo ensino-aprendizagem ocorre, por meio do uso da linguagem escrita, o que caracteriza um rompimento com a tradição acadêmica presencial. Peters, enfatiza que a EaD é voltada para os excluídos do sistema tradicional de ensino, pois a grande clientela deste sistema são adultos com responsabilidades profissionais e familiares, pessoas que buscam atualização de forma rápida e barata, porém, todos buscam na EaD uma possibilidade de aprendizagem permanente.

Para Peters (2006), a EaD possibilita o estudo acessível para mais pessoas, bem como a independência do lugar de estudo, a flexibilidade da metodologia e um amplo intercâmbio de ideias ou abertura para novas, além da facilidade e praticidade relacionada ao tempo e ao custo, levando em conta as propostas de igualdade de oportunidades, que tornam os estudantes mais autônomos, buscando uma maior comunicação.

Preti (2000) e Belloni (2002) apontam que a EaD surgiu como uma forma de educação mais barata, voltada para adultos e focada para atingir públicos impossibilitados ou com dificuldades de acesso ao ensino tradicional. Logo, a comunicação é um elemento fundamental e é abordada por diversos tipos de mídias como materiais impressos, rádio, vídeo, TV, computador, entre outros.

Segundo (Tarouco, Estabel e Moro, 2003, Belloni, 2006) o processo de ensino-aprendizagem da $\mathrm{EaD}$, ocorre de forma síncrona e assíncrona, o que oferece ao discente a oportunidade de estudar conforme a sua disponibilidade, sendo importante criar uma rotina de estudos, visto que o mesmo, deve gerenciar o seu processo de ensino-aprendizagem.

$\mathrm{O}$ ensino a distância requer do aluno uma figura mais autônoma no processo de ensino aprendizagem, buscando florear no aluno a sua capacidade de autodireção e autodeterminação.

Diversos autores, assim como Peters (2003) destaca que é muito importante para o discente da modalidade a distância:

$>$ Desenvolver as habilidades para pensar e agir independentemente;

$>$ Ser objetivo sobre seus próprios requisitos de aprendizagem;

$>$ Ser proativo;

$>$ Reconhecer as diferenças qualitativas rapidamente; 
$>$ Elencar os pontos positivos e negativos no processo de ensino aprendizagem;

> Estar inserido na cultura de comunicação digital.

Observa-se que a EaD exige uma postura mais pró-ativa por parte dos estudantes, desenvolvendo a sua percepção da sua parcela de responsabilidade no processo ensino-aprendizagem.

\subsection{Docentes e Discentes Da Ead}

Na modalidade EaD, os professores devem assumir suas funções e os discentes, necessariamente, precisam desenvolver uma consciência mais ampla de sua atuação.

Assim como na modalidade presencial, existe toda uma equipe responsável pela elaboração e execução dos cursos. Analisando a história desta modalidade, observamos que o papel dos professores está muito ligado às propostas educacionais predominantes do que o fato do curso ser conduzido por um sistema ou outro. O professor pode atuar como um educador, orientador, investigador do desenvolvimento entre tantas outras funções.

Sobre a interação entre estudantes e docentes, Moran (2002, p. 45, sugere:

Educação a distância não é um "fast-food" em que o aluno se serve de algo pronto. É uma prática que permite um equilíbrio entre as necessidades $\mathrm{e}$ habilidades individuais e as do grupo - de forma presencial e virtual. Nessa perspectiva, é possível avançar rapidamente, trocar experiências, esclarecer dúvidas e inferir resultados. De agora em diante, as práticas educativas, cada vez mais, vão combinar cursos presenciais com virtuais, uma parte dos cursos presenciais será feita virtualmente, uma parte dos cursos a distância será feita de forma presencial ou virtual-presencial, ou seja, vendo-nos e ouvindonos, intercalando períodos de pesquisa individual com outros de pesquisa e comunicação conjunta. Algum curso poderá fazê-los sozinhos, com a orientação virtual de um tutor, e em outros será 
importante compartilhar vivências, experiências, ideias.

Moran apresenta uma convergência entre a $\mathrm{EaD}$ e a educação presencial, gerando modelos definidos primordialmente segundo as necessidades pedagógicas, mas incluindo, sempre, o compartilhamento e o diálogo entre alunos e professores. Azevedo (2009), nos mostra que as atividades de práticas de ensino desenvolvidas pelo tutor ainda se encontram imersas em situações de isolamento e desprovida de ação de reflexão e crítica, sugerindo a necessidade de se rever uma racionalidade nas relações pessoais e profissionais.

Em todos os âmbitos da educação, tanto presencial, quanto a distância, o papel do professor é definido pelos projetos que ele propõe, em especial os pedagógicos e educacionais. Para Belloni (2006), a aceitação e utilização dos meios tecnológicos de informação e comunicação permitiu uma organização estrutural mais completa para os cursos EaD, e com isso o aumento das tarefas do docente.

Belloni, destaca algumas subdivisões das funções do corpo docente na EaD:

$>$ Realização e aceitação dos cursos e materiais;

$>$ Organização e planejamento da distribuição dos materiais;

> Acompanhamento dos acadêmicos no processo ensinoaprendizagem.

A partir dessas categorias apresentadas podemos classificar diversas funções para os docentes como:

$>$ Professor Formador;

$>$ Professor Conteudista;

$>$ Professor Pesquisador;

$>$ Professor Tutor.

Dentro estas funções apresentadas, a função que mais tem destaque hoje na $\mathrm{EaD}$, e que está sendo abordada neste trabalho é a do professor tutor.

Esse professor, chamado agora em diante de "tutor" é o responsável pelo acompanhamento dos discentes ao longo da sua vida acadêmica, cabendo a ela a responsabilidade de mediar o desenvolvimento do curso, 
devendo orientar os alunos em suas tarefas e estudos, esclarecer dúvidas, explicar os materiais e dúvidas relativas aos conteúdos abordados, avaliar o fórum, corrigir a prova e ainda por cima motivar os alunos, fazendo com que o ensino EaD, deixe de ser frio e solitário, passando a ser mais humanizado.

\subsection{Professor Tutor na EaD}

A palavra tutor vem do latim tutoris, que significa aquele que defende, que preserva, que sustenta, que socorre (Pedrosa, 2003), porém, conforme (Emerenciano, Sousa e Freitas, 2001), o trabalho desenvolvido pelos tutores da educação a distância é, de fato, o trabalho de um professor e educador.

Percebemos que nos modelos da EaD, há uma busca constante por minimizar as distâncias entre o aluno e o professor, porém, esta tentativa era feita por meio de textos, logo, vários autores percebem que a ferramenta de melhor resultado é o contato com o tutor, por isso, o tutor tem um papel muito importante no processo de ensino-aprendizagem na educação a distância, se comparando ao do professor. Assim, vários autores resguardam que o papel do tutor pode ser comparado ao do professor.

Vários autores comungam da ideia que na $\mathrm{EaD}$, ser tutor significa ser professor e educador, visto que este processo exige uma orientação educativa relacionada aos conteúdos, considerando as necessidades dos estudantes, além de habilidades de estimular e envolver os alunos nas atividades.

Martins (2003) percebe que o tutor tem um papel importantíssimo na EaD, como sendo ele o responsável pela garantia da inter-relação com os alunos e com o sistema, a famosa ponte. Essa ação permite a articulação fundamental entre os elementos envolvidos no processo e o sucesso do processo de ensino aprendizagem.

Os alunos tem acesso aos conteúdos de estudo por meio dos materiais dos cursos, logo, cabe ao tutor fazer o estímulo do desejo do aluno de aprender e de ir além do que lhe foi proposto. Isso deve ser feito individualmente, articulando com as particularidades de cada aluno, mas, não deixando de lado o foco principal que é o conteúdo que está sendo trabalhado. Em virtude desta função, muitos autores defendem que cada 
tutor deve ter um número reduzido de alunos para dar mais atenção a eles, alguns afirmam que cada tutor deva cuidar entre 20 e 30 alunos, outros já são mais audaciosos e apresentam entre 200 e 500 alunos, mas, sabemos que muitas vezes essa realidade não existe.

A atividade do tutor é o principal meio de incentivar e manter o estudante assíduo nas atividades e nos diálogos propostos, sempre pelos contatos e diálogos relacionados com o tutor e os estudantes. O autor Munhoz (2003) destaca que um bom material e uma boa qualificação dos profissionais não é o suficiente para garantir a permanência dos alunos com a instituição. O tutor é a forma mais segura de acompanhar, desenvolver e fixar o interesse dos alunos e fazer com que se fixem na instituição.

A motivação proposta pelo tutor inclui a capacidade de estimular os discentes na busca por respostas e aprofundar-se nos debates, além de auxiliá-los nos momentos de dificuldades tanto pedagógica, acadêmicas, tecnológicas e muitas vezes pessoais. Como dito acima, o tutor deve tornar o processo EaD mais humano, mas próximo, mais aconchegante, fazendo com que os alunos realmente se sintam dentro de uma sala de aula e além de tudo nunca percebam que estão sós.

Balbé (2003) aborda que o tutor não se afunila em apenas fornecer o auxílio acadêmico, mas se expande para a compreensão das capacidades e limitações do ser humano, o tutor deve ser acolhedor.

Outro ponto importante a ser mencionado é em relação a formação do tutor. Logo, compreendemos que o tutor deve apresentar as práticas do sistema presencial na educação a distância, logo, neste modelo ele exerce um papel de mediação entre o estudante e o conhecimento, entre o estudante e a instituição, entre o estudante e o professor, entre o estudante e as tecnologias, portanto, percebemos que o tutor é o suporte, é quem faz a baliza entre o aluno e todos os outros atores pertencentes ao meio do processo ensino aprendizagem da educação a distância.

Arredondo (2003) defende que todos os envolvidos na educação a distância, devem ter suas formações específicas na área em que trabalham, podendo assim, fornecer um maior suporte para o aluno, proporcionado a fixação e o seu contentamento. A formação destes profissionais deve abranger as áreas da didática, organizacional e tecnológica, entre outras pertinentes ao cargo. 
Segundo Arredondo (2003), a formação dos profissionais envolvidos na $\mathrm{EaD}$ deve contemplar:

> Desenho, programação e execução de um curso a distância;

$>$ Elaboração de materiais didáticos para a EaD;

$>$ Sistema de intercomunicação didática a distância;

$>\mathrm{O}$ estudante, suas características peculiares, a aprendizagem

à distância, a ajuda tutorial;

$>$ Os professores, suas funções e competências;

$>$ O pessoal do trabalho administrativo e seus serviços;

> A instituição, seu corpo docente e seus processos;

$>$ Centros de tutoria, competências e intercomunicação;

$>$ Distribuição dos materiais didáticos;

$>$ Assistência tecnológica e incorporação de novas tecnologias

Arredondo (2003), também sugere algumas áreas de capacitação:

$>$ Fundamentos, estruturas e possibilidades na EaD;

$>\mathrm{O}$ estudante adulto e suas características;

$>$ Teorias de aprendizagem;

$>$ Conhecimento teórico e prático em comunicação;

$>$ Relação com a tecnologia;

$>$ Conhecimentos científicos, tecnológicos, metodológicos e práticos do curso;

> Técnicas de organização de informações, tempo e ações;

$>$ Técnicas de tutoria;

$>$ Técnicas de motivação e

$>$ Técnicas de avaliação.

Belloni (2006) é incisivo quando diz que para desenvolver propostas educativas adequadas, é necessário que os professores mantenham atualizadas as três dimensões dimensões que são:

$>$ Dimensão pedagógica;

$>$ Dimensão tecnológica;

$>$ Dimensão didática.

Tudo aquilo que envolve a formação dos tutores e dos demais profissionais que trabalham no âmbito da EaD, agregam diferentes 
dimensões e ajudam a construir as competências.

\subsection{O Tutor Mediador}

O tutor deve assumir uma postura de facilitador, de mediador, buscando sempre estar inovando e adaptando-se as novas estruturas tecnológicas. Ele deve estar atendo e pronto para receber informações dos novos meios do qual está inserido e junto aos estudantes decodificálos, alcançando os objetivos comuns.

Segundo Masseto (2000, p.144-145) a mediação é uma:

Atitude, o comportamento do professor que se coloca como um facilitador, incentivador ou motivador da aprendizagem, que se apresenta com disposição de ser uma ponte entre o aprendiz e sua aprendizagem - não uma ponte estática, mas uma ponte "rolante", que ativamente colabora para que o aprendiz chegue aos seus objetivos.

Alguns autores comentaram sobre a mediação e vamos abordar alguns: Belloni (2001), afirma que mediar significa codificar as mensagens pedagógicas, traduzindo sob diversas formas, segundo o meio escolhido. Já para Tébar (2011), a mediação tem o objetivo de construir habilidades no sujeito, a fim de promover sua plena autonomia. Logo, percebemos que a ação de mediação, é uma ação para humanizar o processo de ensino aprendizagem na educação a distância.

Tébar (p.77), afirma que a educação mediada integra três elementos:

O educador, e toda pessoa que promove um desenvolvimento, é um intermediário entre o aluno e o saber, entre o aluno e o meio e entre o aluno e seus colegas de sala de aula.

$\mathrm{O}$ educador mediador regula as aprendizagens, favorece o progresso e o avalia, proporciona uma relação de ajuda facilitadora de aprendizagem e, o que é sua tarefa essencial, ajuda a organizar o contexto em que o sujeito se desenvolverá.

$\mathrm{O}$ próprio mediador é o primeiro modificado, o 
que mais necessita de auto modificação para poder chegar ao educando. A ausência de mediação cria privação cultural e subdesenvolvimento das capacidades do indivíduo.

A mediação deve ser vista como uma ação que interessa a todos os envolvidos na EaD, Segundo Neder (2000), acompanhar o discente significa:

$>$ Saber como ele estuda;

$>$ Que dificuldade apresenta quando busca orientação;

$>$ Como e quando interage com os colegas para estudar;

$>$ Consulta-se a bibliografia de apoio;

$>$ Realizam-se as tarefas e exercícios propostos;

$>$ Se for capaz de relacionar teoria/prática.

Para Kenski (2010), a mediação do processo de ensino aprendizagem ocorre de forma direta e indireta por todos os atores responsáveis pelo processo educacional. Portanto podemos dizer que a mediação é contemplada pelo planejamento das sulas, pela elaboração dos materiais didáticos e pelas oportunidades de interação e avaliação dos discentes.

Moreira (2006) considera a aprendizagem um processo por meio do qual uma nova informação relaciona-se de alguma maneira ao conhecimento do indivíduo. Assim, os novos conhecimentos que se adquirem, relacionam-se com o conhecimento prévio que o aluno possui.

\subsection{O Tutor e a Tutoria.}

Com a expansão da educação à distância e a sua relação com as TICs, alguns autores tratam a modalidade como uma revolução tecnológica na qual as tecnologias são protagonistas exclusivas, sem considerar os desmembramentos e especificidades pertinentes à pedagogia e aos processos de aprendizagem. As tecnologias podem favorecer apoiar, fomentar a expansão da educação, mas, por si só, não oferece oportunidade aos aprendizes de se desenvolver como indivíduos críticos e autônomos. Assim como aquele que está em contato direto com o acadêmico na $\mathrm{EaD}$, o tutor mediador, surge como figura fundamental, conforme nos mostra os próprios Referenciais (BRASIL, 2007, p. 21): 
O corpo de tutores desempenha papel de fundamental importância no processo educacional de cursos superiores a distância e compõem quadro diferenciado, no interior das instituições. O tutor deve ser compreendido como um dos sujeitos que participa ativamente da prática pedagógica. Suas atividades desenvolvidas a distância e/ ou presencialmente devem contribuir para o desenvolvimento dos processos de ensino e de aprendizagem e para o acompanhamento e avaliação do projeto pedagógico.

Segundo Schlosser (2012), o tutor mediador surgiu no final do século XV. Sua função era de prestar uma assessoria acadêmica e pastoral a grupos de alunos, de maneira individualizada e sob a coordenação de um docente. Diante da eficácia desse modelo de apoio, no século XIX, as universidades formalizaram a tutora em seus quadros docentes. Tendo a função de orientador e acompanhador dos trabalhos acadêmicos, o sentido da tutoria foi sendo incorporado na $\mathrm{EaD}$ e é, atualmente, central na modalidade. Assim, a função do tutor como um indivíduo que oferecia apoio a uma minoria foi sendo integrada em um modelo de educação criado, essencialmente para as massas.

Costa (2010) traduz muitas expectativas sobre a tutoria, fazendo acreditar em novos olhares e que as mudanças podem acontecer:

Ser tutor é ser uma pessoa especial, alguém que acima de tudo acredita na Educação, que ainda leva consigo a esperança de modificar uma sociedade, transferindo toda sua experiência de vida a seus alunos e atuando como facilitador num processo de integração com o ambiente virtual. No início das aulas, faz parte da vida do tutor acalmar os alunos, pois $90 \%$ deles está há muitos anos sem estudar e com certeza precisam de um incentivo, precisam começar a acreditar em si, a acreditar que são capazes $O$ tutor tem que ensinar a aprender, elogiar cada progresso, por menor que seja, tem que resgatar a auto estima de cada um e, muitas vezes, parar para ouvir seus problemas, apoiá-los nas horas 
difíceis e comemorar as vitórias juntos.

Ser tutor é resgatar vidas, é devolver a esperança para alguém que já havia perdido, é concretizar sonhos antigos e criar novos, é mostrar novas oportunidades, através das dinâmicas empregadas em aula, tornando-os pessoas mais críticas. Infelizmente, o tutor não é valorizado como deveria, porque ninguém faz ideia das suas obrigações, pois além da parte humana também existe toda uma parte acadêmica e burocrática, a qual o tutor deve estar sempre atento a fim de não causar danos à vida escolar dos alunos. O que deve ser mudada é a visão que se tem do tutor, é a valorização que ele não tem, não tem um piso salarial, por vezes não tem o material adequado para que ele possa dar aula, mas mesmo sem livro, sem DVD, sem computador o Tutor é teimoso, é persistente, ele dá aula contando apenas consigo próprio e nem assim é valorizado, mas ele chega lá e com muito orgulho faz a entrega de cada diploma como uma vitória pessoal.

O tutor mediador é de fato, um elemento fundamental nas soluções do problema logístico criado pelo objetivo de se distribuir oportunidades de aprendizagem a números significativos de estudantes e, assim, democratizar o acesso ao conhecimento. As funções do tutor mediador consistiam em esclarecer dúvidas, verificar as atividades realizadas pelos alunos, motiva-los, realizar trabalhos práticos para facilitar a compreensão da teoria e conduzir a avaliação formativa continuada. As orientações dos Referenciais com relação às funções da tutoria são consistentes com esse modelo (BRASIL, 2007, p. 21):

A tutoria a distância media o processo pedagógico junto aos estudantes, sendo sua principal atribuição o esclarecimento de dúvidas e a promoção de espaços de construção coletiva de conhecimento, participar do processo avaliativo de ensino-aprendizagem junto com os docentes e selecionar material de apoio. 
O papel do tutor mediador é visto pela sua mediação: por um lado, o tutor acompanha e apoia o aluno; por outro, dependendo da estrutura de EaD em questão, o tutor também participa do processo de design e desenvolvimento de módulos ou cursos. Segundo Masetto (2000), a mediação pedagógica é a atitude e o comportamento do docente que se coloca como um facilitador, um motivador da aprendizagem, de maneira ativa, colaborando para que estudante alcance seus objetivos, ainda os referenciais atribuem também a função de esclarecimento de dúvidas e a promoção de espaços de construção coletiva de conhecimento, além da seleção de materiais de apoio e sustentação teórica aos conteúdos, como participar dos processos avaliativos.

Netto, Giraffa e Faria (2010), ressaltam que o uso de tecnologias da comunicação requer que professores, alunos e tutores sejam capazes de se perceber como parte de uma comunidade virtual de aprendizagem colaborativa, e desempenhar novos papéis. Para isso, o tutor precisa de competência técnica para o uso de computadores, metodologias adequadas, organização, disciplina, disponibilidade e flexibilidade, dentre outros aspectos, que contribuam para a interatividade do processo. Assim, o tutor mediador, deve buscar propor desafios para os alunos descobrirem mais, de modo que o tutor precisa problematizar situações, investigar, ir além de simplesmente tirar dúvidas. Para isso, o tutor mediador deve possuir um amplo conhecimento do conteúdo e dos recursos virtuais, mediando as interações e resolvendo os conflitos que surgirem.

Vários autores ressaltam que o tutor mediador atua também como um fomentador social, facilitando e dando espaço a aspectos pessoais e sociais no AVA. No entanto, argumentam que a maioria dos docentes atuantes como tutores mediadores não recebem uma formação específica com recursos tecnológicos, para começar, e, portanto, têm pouca ou nenhuma intimidade com ambientes virtuais e suas funcionalidades.

Faz-se necessário refletir sobre as condições de trabalho da tutoria. Com base legal, o artigo 67 da LDBEN enfatiza que os sistemas de ensino irão promover a valorização dos profissionais da educação e define os seguintes aspectos:

I - ingresso exclusivamente por concurso público de provas e títulos;

II - aperfeiçoamento profissional continuado, 
inclusive com licenciamento periódico renumerado para esse fim;

III - piso salarial profissional;

IV - progressão funcional baseada na titulação ou habilitação, e na avaliação de desempenho; $\mathrm{V}$ - período reservado a estudos, planejamento e avaliação, incluído na carga horária de trabalho; VI - condições adequadas de trabalho.

No que diz respeito à tutoria na educação à distância, ao utilizar o termo "tutor" e "docente" como categorias separadas, os próprios referenciais parecem contribuir para a ambivalência da figura do tutor e seu papel como professor. Entretanto, conforme sugere Lemgruber (2008), o tutor é um professor, já que sua mediação é uma função docente, tanto na tutoria de uma disciplina (tutor mediador), quando na tutoria presencial (tutor presencial). Assim, enquanto a tutoria é concebida como imprescindível à $\mathrm{EaD}$, permanecem muitas lacunas referente às suas condições de atuação.

Outro aspecto também problemático relacionado às tarefas atribuídas ao tutor e que constitui, para alguns, um questionamento e crítica feitos à $\mathrm{EaD}$ como um todo, relaciona em torno do termo "autonomia". Não obstante a variedade de sentidos possíveis para o termo, a predeterminação, na $\mathrm{EaD}$, de várias aspectos considerados centrais ao trabalho docente pode ser considerada como em direta oposição à ideia de "autonomia docente", em particular, naquilo que diz respeito à liberdade para se tomar decisões (FREIRE,1996, p.67).

Ninguém é sujeito da autonomia de ninguém. Por outro lado, ninguém amadurece de repente, aos 25 anos. A gente vai amadurecendo todo dia, ou não. A autonomia, enquanto amadurecimento todo dia, ou não A autonomia, enquanto amadurecimento do ser para si é processo, é vir a ser. Não ocorre em data marcada. É neste sentido que uma pedagogia da autonomia tem de estar centrada em experiências estimuladoras da decisão e da responsabilidade, vale dizer, em experiências respeitosas da liberdade. 
A fala de Freire, buscou, dentre outros objetivos, compreender o que pensam os tutores acerca de suas ações, suas possibilidades e sua contribuição aos processos educacionais conduzidos na EaD.

\subsection{A EAD e os Referenciais de Qualidade}

Não há um modelo único de educação a distância. Os programas podem apresentar diferentes desenhos e múltiplas combinações de linguagens e recursos educacionais e tecnológicos. Apesar da possibilidade de diferentes modos de organização, um ponto deve ser comum a todos àqueles que desenvolvem projetos nessa modalidade: é a compreensão da educação como fundamento primeiro, antes de se pensar no modo de organização: a distância.

Devido à complexidade e à necessidade de uma abordagem sistêmica, os referenciais de qualidade para a educação a distância devem compreender categorias que envolvem, fundamentalmente, aspectos pedagógicos, recursos humanos e infraestrutura. Para dar conta destas dimensões, devem estar integralmente expressos no Projeto Político Pedagógico de um curso na modalidade a distância os seguintes requisitos:

$>$ Concepção de educação e currículo no processo de ensino e aprendizagem;

> Sistemas de Comunicação;

$>$ Material didático;

$>$ Avaliação;

$>$ Equipe multidisciplinar;

$>$ Infraestrutura de apoio;

> Gestão acadêmico-administrativa;

$>$ Sustentabilidade financeira.

A concepção de educação é que norteia o processo educacional, logo, ela deve ser comprometida socialmente e, no caso específico da $\mathrm{EaD}$, jamais poderá primar por uma noção estreita de formação de mãode-obra, pois, deve ir além disso, formando sujeitos atuantes e produtores de conhecimento.

A abrangência dada aos aspectos enfatizados pelos referenciais de qualidade, denotam um enfoque claramente sistêmico, preocupados em articular cada um dos vários aspectos que compõem a realização de 
cursos e projetos de EaD. Petri (2010, p. 163), "ao falarmos de material didático, estamos nos referindo a uma diversidade de meios tecnológicos que podem ser utilizados no ato de ensinar, tendo como objetivo a aprendizagem por tarde do estudante". Seja na EaD ou no ensino presencial, o material didático é fundamental para que o processo ensinoaprendizagem efetivamente se estabeleça. Entretanto, na EaD o material didático assume como protagonista especial, notadamente pela ausência de um professor presencial, conforme enfatizado por Silva (2010): “é na $\mathrm{EaD}$ que este constitui-se como indispensável para a construção do conhecimento. Logo a produção do material didático é um fator decisório na qualidade de um curso na $\mathrm{EaD}$, já que cabe a esse recurso grande parte do aprendizado do aluno".

Com relação à concepção de educação e currículo no processo de ensino e aprendizagem, o projeto deve apresentar claramente sua opção epistemológica de educação, de currículo, de ensino, de aprendizagem, de perfil do estudante que deseja formar.

O uso inovador da tecnologia aplicada à educação, e mais especificamente, à educação a distância deve estar apoiado em uma filosofia de aprendizagem que proporcione aos estudantes a oportunidade de interagir, de desenvolver projetos compartilhados, de reconhecer e respeitar diferentes culturas e de construir o conhecimento.

O conhecimento é o que cada sujeito constrói - individual e coletivamente - como produto do processamento, da interpretação, da compreensão da informação. É, portanto, os significados que atribuímos à realidade e como o contextualizaram. Com isso o estudante é o foco do processo pedagógico e frequentemente a metodologia da educação a distância representa uma novidade, é importante que o projeto pedagógico do curso preveja, quando necessário, um módulo introdutório que leve ao domínio de conhecimentos e habilidades básicos, referentes à tecnologia utilizada e/ou ao conteúdo programático do curso, prevendo atividades de acolhimento do estudante, assegurando a todos um ponto de partida comum.

O desenvolvimento da educação a distância em todo o mundo está associado à popularização e democratização do acesso às tecnologias de informação e de comunicação. Tendo o estudante como centro do processo educacional, um dos pilares para garantir a qualidade de um 
curso a distância é a interatividade entre professores, tutores e estudantes. Portanto, o princípio da interação e da interatividade é fundamental para o processo de comunicação e devem ser garantidos no uso de qualquer médio tecnológico a ser disponibilizado.

Logo, o curso em EaD, precisa estar ancorado em um sistema de comunicação que permita ao estudante resolver, com rapidez, questões referentes ao material didático e seus conteúdos, bem como aspectos relativos à orientação de aprendizagem como um todo, articulando o estudante com docentes, tutores, colegas, coordenadores de curso e responsáveis pelo sistema de gerenciamento acadêmico e administrativo.

Em um curso a distância, o estudante deve ser o centro do processo educacional e a interação deve ser apoiada em um adequado sistema de tutoria e de um ambiente computacional, especialmente implementado para atendimento das necessidades do estudante.

O material didático deve estar concebido de acordo com os princípios epistemológicos, metodológicos e políticos explicitados no projeto pedagógico, de modo a facilitar a construção do conhecimento e mediar a interlocução entre estudante e professor, devendo passar por rigoroso processo de avaliação prévia, com o objetivo de identificar necessidades de ajustes, visando o seu aperfeiçoamento. Logo, o material didático, deve desenvolver habilidades e competências específicas, recorrendo a um conjunto de mídias compatível com a proposta e com o contexto socioeconômico do público-alvo. Sendo necessário para atingir estes objetivos, que os decentes responsáveis pela produção dos conteúdos trabalhem integrados a uma equipe multidisciplinar, contendo profissionais especialistas em desenho instrucional, diagramação, ilustração, desenvolvimento de páginas e outras funcionalidades pertinentes.

$\mathrm{Na} \mathrm{EaD}$, o modelo de avaliação da aprendizagem deve ajudar o estudante a desenvolver graus mais complexos de competências cognitivas, habilidades e atitudes, possibilitando-lhe alcançar os objetivos propostos. Para tanto, esta avaliação deve comportar um processo contínuo, para verificar o progresso dos estudantes e estimulá-los a serem ativos na construção do conhecimento.

A avaliação é um instrumento indispensável de gestão necessária para se mensurar os esforços da organização na sua qualidade (MEYER 
JR., 1993). O processo de avaliação constitui um instrumento fundamental para promover as transformações capazes de corrigir procedimentos ineficientes e ineficazes. Freitas e Silveira (1997) destacam que a avaliação foi um tema muito importante para as universidades brasileiras nas últimas décadas. Ela segundo os autores é um instrumento necessário para à orientação de rumos que conduz à eficiência e qualidade dos serviços

As instituições devem planejar e implementar sistemas de avaliação institucional. Esta avaliação deve configurar-se em um processo permanente e consequente, de forma a subsidiar o aperfeiçoamento dos sistemas de gestão e pedagógico, produzindo efetivamente correções na direção da melhoria de qualidade do processo.

De acordo com Belloni (1994) as instituições de ensino devem buscar desenvolver um sistema de avaliação que possibilitem o aperfeiçoamento da qualidade da educação - isto é, do ensino, da aprendizagem, da pesquisa e da gestão institucional - com a finalidade de transformar a escola atual em uma instituição comprometida com a democratização do conhecimento e da educação, assim como com a transformação da sociedade. Essa é a função social da avaliação e é necessário aprender como implementá-la.

Cunha (1998) afirma que a avaliação da qualidade do sistema educativo verifica a adequação dos conteúdos curriculares dos distintos ciclos, níveis e regimes especiais às necessidades sociais e às demandas sociais da comunidade, assim como a aprendizagem dos alunos e a qualidade da formação docente. Numa universidade, a implantação de um programa de qualidade deve estar voltada, no mínimo, para o provimento de currículos adequados à garantia do aprendizado e para a demonstração do compromisso total da instituição de ensino com os resultados.

A avaliação nas instituições de ensino não é um fim em si mesmo; ela somente faz sentido na medida em que apoia o desenvolvimento do ensino. Ela deve ser parte integrante dos processos de planejamento, quer das tarefas acadêmicas, quer das de apoio, e deve incorporar uma visão que permita avaliar avanços, identificar obstáculos e promover ações com vistas à melhoria gradativa da qualidade acadêmica.

$\mathrm{Na}$ educação a distância, há uma diversidade de modelos, que resulta em possibilidades diferenciadas de composição de recursos 
humanos necessários à estruturação e funcionamento de cursos nessa modalidade. Essa composição segundo os referenciais de qualidade denominam-se de equipe multidisciplinar que é composta pelos docentes, tutores e o pessoal técnico administrativo.

Os Referenciais de Qualidade para a Educação Superior a Distância (MEC, 2007 p. 21) consideraram que os professores veem suas funções se expandirem em programas a distância, o que requer que sejam altamente qualificados. Por sua vez, neste contexto caracteriza-se o tutor como um agente fundamental nos processos de aprendizagem, avaliação e interação. Neste documento fica estabelecido que:

O tutor deve ser compreendido como um dos sujeitos que participa ativamente da prática pedagógica. Suas atividades desenvolvidas a distância e/ou presencialmente devem contribuir para o desenvolvimento dos processos de ensino e de aprendizagem e para o acompanhamento e avaliação do projeto pedagógico.

O corpo de tutores desempenha um papel de fundamental importância no processo educacional nos cursos da educação a distância. Devendo eles ser compreendidos como um dos sujeitos que participam ativamente das práticas pedagógicas, sendo que suas atividades presenciais ou a distância, devam contribuir para o desenvolvimento dos processos de ensino e de aprendizagem e para o acompanhamento e avaliação do projeto pedagógico.

Os tutores são classificados como tutor a distância (mediador) e o tutor presencial.

O tutor mediador atua a partir da instituição, mediante os processos pedagógicos junto a estudantes geograficamente distantes, e referenciados aos polos descentralizados de apoio presencial. Sendo suas principais funções, o esclarecimento de dúvidas por meio dos fóruns de discussão, pela internet, mediar a aula ao vivo passando para o professor as dúvidas dos alunos e fazer a ponte entre o aluno e o professor, entre o aluno e a instituição. Tendo ele também a responsabilidade de promover espaços de construção coletiva de conhecimento, selecionar material de apoio e sustentação teórica aos conteúdos. 
Já o tutor presencial atende os alunos nos polos de apoio, em horários pré-estabelecidos. Devendo ele conhecer o projeto pedagógico do curso e com isso auxiliar os estudantes no desenvolvimento de suas atividades individuais, fomentando o hábito da pesquisa. Participa dos momentos presenciais obrigatórios como, por exemplo, a prova presencial.

O corpo técnico administrativo tem por função oferecer o apoio necessário para a realização dos cursos ofertados, atuando na sede da instituição junto à equipe docente responsável pela gestão do curso e nos polos.

A ONU juntamente com a UNESCO, propõe uma justificativa abrangente para o pensar sobre qualidade na educação (UNESCO, 2001, p. 1):

Aqualidade se transformou em um conceito dinâmico que deve se adaptar permanentemente a um mundo que experimenta profundas transformações sociais e econômicas. É cada vez mais importante estimular a capacidade de previsão e de antecipação. Os antigos critérios de qualidade já não são suficientes. Apesar das diferenças de contexto, existem muitos elementos comuns na busca de uma educação de qualidade que deveria capacitar a todos, mulheres e homens, para participarem plenamente da vida comunitária e para serem também cidadãos do mundo.

Gadotti (2001) sugere que a qualidade na educação não pode ser boa se a qualidade de todos os envolvidos (professor, aluno, comunidade) é ruim. Não se pode separar a qualidade da educação da qualidade como um todo. No entanto as dificuldades em se definir "qualidade" são muitas, conforme Netto, Giraffa e Faria (2010, p. 19) concisamente apresenta:

Qualidade você sabe o que é; entretanto não sabe $o$ que é. Não se descarte a contradição. Ainda assim, algumas coisas são melhores que outras, têm mais qualidade. Quando você tenta dizer o que a qualidade é, separada das coisas que a possuem, tudo se desvanece. Assim, não haveria nada para se 
dizer sobre ela. Se você não consegue dizer o que é qualidade, como vai saber o que é, ou como vai saber, pelo menos, se ela existe? Se ninguém sabe o que ela é, então para quaisquer fins práticos, ela não existe absolutamente. Em que se baseiam os graus dela? Por que as pessoas pagam fortunas por algumas coisas e atiram ao lixo outras? Obviamente, algumas coisas são melhores que outras. Mesmo assim, em que consiste esta melhoridade? Dessa maneira, você vai tecendo rodas mentais, sem encontrar o ponto de apoio em que findar a tração. Qualidade, qualidade, que é qualidade?

Qualidade pode ser associada à adequação, responsabilidade, eficiência, eficácia e excelência: pode-se enfatizar que a experiência educacional, para ser considerada de qualidade, requer-se que ela tenha utilidade ou valor para aqueles que nela tomam parte. Sanyal e Martin (2006) identificam algumas definições de qualidade do produto - sem defeito, satisfazendo a necessidade dos clientes, e do serviço - ajustandose às especificações, oferecendo um valor a mais e, como o produto, satisfazendo a necessidade dos clientes.

Chalmers e Johnston (2012) capturam os sentidos do termo na educação em cinco classes:

$>$ Excelência, ou seja, qualidade como algo excepcional, único e elitista;

$>$ Consistência, ou seja, qualidade como resultado perfeito, sem problemas;

$>$ Adequação, isto é, qualidade como a concretização de metas pré-definidas;

> Valor de retorno de investimentos;

> Transformação, isto é qualidade como o aumento do poder do estudante ou a criação de novos conhecimentos.

Segundo as autoras, o ES é usualmente julgado em termos de adequação e/ou valor do retorno de investimentos, em particular, nos contextos de gestão de governos e instituições privadas.

Juliatto defende a necessidade de indicadores que possibilitem 
monitorar e melhorar a qualidade no serviço educacional, sugerindo duas categorias de métodos:

Métodos quantitativos têm sido usados no trato de matérias em que os dados já existem ou facilmente podem ser reunidos, como nos seguintes exemplos: teste de aptidão, registros estudantis, despesas registradas, coleções de biblioteca, dependências educativas, proporção de doutores no corpo docente e outros. Os métodos qualitativos não enfatizam a objetividade no mesmo grau. Em vez disso, eles tentam capturar outras manifestações subjetivas da qualidade, mais infensas de serem traduzidas por medições numéricas, como a satisfação do estudante, o envolvimento pessoal do estudante e a interação do discente com o corpo docente. (JULIATTO, 2005, p. 75 apud NETTO; GIRAFFA; FARIA, 2010, p. 23).

Kanwar e Koul (2006) justificam a necessidade de avaliação da educação à distância como consequência do próprio processo de democratização da educação, da demanda de programas e cursos que atendam às necessidades do mercado de trabalho, bem como das aspirações e do novo perfil do estudante. Para os autores no contexto global, a EaD tem se desenvolvido no sentido de avançar para além dos processos formais de qualidade, e no sentido de uma cultura de qualidade. Por outro lado, no Brasil estão em uso, como indicadores de qualidade, os exames nacionais em nível superior, que, segundo Torres (2010, p. 256), podem garantir a consolidação da EaD:

No Brasil o ensino superior sofre avaliações constantes por meio de mecanismos regulares de verificação de qualidade. Tais mecanismos garantem as avaliações das condições operacionais das instituições, as características de titulação e regime de trabalho dos docentes, e também o status de aprendizagem dos alunos matriculados. A regulamentação desses processos está estabelecida na Lei 10.861/2004, que instaurou o Sistema 
Nacional de Avaliação do Ensino (SINAES). O Exame Nacional de Desempenho de Estudantes (ENADE) é o instrumento específico para avaliar o desempenho dos alunos. Tal instrumento é aplicado indistintamente em alunos de cursos presenciais e em alunos de cursos a distâncias equivalentes. Como todos fazem a mesma prova, nas mesmas datas, locais, horários e demais condições, é possível comparar os desempenhos alcançados pelos alunos das duas modalidades.

No Brasil, os programas de EaD são regulamentados, avaliados e supervisionados pelo MEC, que é responsável pelo credenciamento de cursos. Isso exige um processo no qual a instituição precisa evidenciar que sua proposta de curso é consistente com os Referenciais de Qualidade.

Além de mobilizar recursos humanos e educacionais, um curso a distância exige infraestrutura material proporcional ao número de alunos.

A infraestrutura refere-se aos equipamentos de televisão, data show, telão, computadores, impressoras, linhas telefônicas, computadores com acesso a internet, etc. Devendo ela estar disponível tanto na sede quanto também nos seus polos de apoio presencial.

O polo de apoio presencial é a unidade operacional para o desenvolvimento descentralizado de atividades pedagógicas e administrativas relativas aos cursos e programas ofertados a distância. Logo, no polo, será ofertado as atividades presenciais obrigatórias, como, a avaliação, defesas de trabalhos de conclusão de cursos, além das orientações dos tutores presenciais e da transmissão das aulas ao vivo.

Essa unidade, portanto, desempenha um papel de grande importância para o sistema de educação a distância. Sua instalação auxilia o desenvolvimento do curso e funciona como um ponto de referência fundamental para o estudante.

As bibliotecas dos polos de apoio devem possuir acervo atualizado, amplo e compatível com as disciplinas dos cursos ofertados. É importante além da biblioteca física que seja disponibilizado para os alunos um acervo digital.

A gestão acadêmica de um projeto de curso de educação a distância deve estar integrada aos demais processos da instituição, ou seja, 
é de fundamental importância que o estudante de um curso a distância tenha as mesmas condições e suporte que o presencial.

A educação superior a distância de qualidade envolve uma serie de investimentos iniciais elevados, para a produção de material didático, na capacitação das equipes multidisciplinares, na implantação dos polos de apoio presencial e na disponibilização dos demais recursos educacionais.

Para garantir o ensino a distância a instituição deve montar uma planilha de custos do projeto como um todo, em consonância com o projeto político-pedagógico e a previsão de seus recursos, mostrando em particular os elementos de investimento e custeio. Após a elaboração da planilha de custo a instituição deve apresentar uma planilha de oferta de vagas.

Ainda que não defina um modelo único de $\mathrm{EaD}$, os referenciais especificam elementos obrigatórios a serem oferecidos por todos os cursos propostos, referindo-se à organização didático-pedagógica, ao corpo docente e de tutores, além de mencionar as instalações físicas a serem disponibilizadas e utilizadas pelos alunos na universidade e em seus polos de apoio presencial. Os projetos político-pedagógicos dos cursos devem apresentar com clareza as opções do currículo, a concepção de educação, os sistemas de comunicação, o material didático, a avaliação, a concepção da equipe multidisciplinar, a infraestrutura de apoio, a gestão acadêmico-administrativa, a sustentabilidade financeira, bem como o perfil do aluno que pretende formar. De modo a atender às exigências dos referenciais, o sistema de comunicação fundamentado em TIC deve permitir ao aluno resolver com rapidez as questões apresentadas pelos materiais didáticos e seus conteúdos, possibilitando sua articulação com os docentes, tutores, colegas, coordenadores e responsáveis pelo sistema acadêmico e administrativo. Em outras palavras, conforme o documento, a metodologia deve estar apoiada em algum meio tecnológico que permita a interação.

Sendo esses referenciais de qualidade comprovadamente eficazes em sua prescrição, acredita-se que a questão levantada possa repercutir no âmbito educacional, alterando nuances de caráter econômico, político e administrativo, uma vez que as instituições de ensino superior podem vir a fazer melhores escolhas em relação ao modelo de gestão adotado e passar a se posicionar com mais propriedade sobre a concepção teórico- 
metodológica e organização dos seus sistemas de EAD.

\section{CONSIDERAÇÕES FINAIS}

Com diferentes olhares, podemos refletir sobre as dinâmicas de diferentes modelos de trabalho, e diferentes formas de vislumbrar a relação entre as práticas da EaD. Quando o tutor concebe a si próprio como um executor de tarefas que foram determinadas e orientadas por um objetivo específico, atua de forma limitada como um tira-dúvidas, respondendo as questões de alunos e corrigindo mecanicamente as provas elaboradas por outros professores, e não é esse olhar e concepção que foi percebido com relação aos tutores da IE pesquisada. Eles têm a clareza das suas funções, sabem o que devem fazer, sabem que não são meros agentes dentro do processo e sim figura importante para desenvolver o processo de ensino aprendizagem e fazer com que os alunos tenham sucesso na sua vida acadêmica.

Almeida e Prado (2007), diz que a EaD não pode ser compreendida simplesmente como uma transferência da abordagem pedagógica presencial para o ambiente virtual: a formação docente específica para a modalidade tanto se faz necessária como urgente. A forma de acesso à tutoria da IES investigada apresenta e instiga o ensino, a formação e a complementação, também relacionando com o referencial, apresenta e propõe aos seus tutores, cursos de alinhamento, tanto presencial como a distância, além de todo suporte para desempenho das suas tarefas. Todos os tutores da IE pesquisada tem formação na área de trabalho, muitos deles têm um curso de licenciatura, estão cursando uma especialização e muitos estão se aperfeiçoando na educação a distância.

O tutor mediador é de extrema importância para o processo ensinoaprendizagem da EaD. Sendo ele responsável pelo acompanhamento do acadêmico, desde o seu ingresso na IE até a sua conclusão. O mesmo trabalha com diversas ferramentas que o auxilia no mapeamento dos alunos sobre acesso ao AVA, atividades, fóruns e dúvidas. Os tutores tem total liberdade para criar materiais ou técnicas que vá auxiliar o acadêmico no processo. Além de contribuir para a compreensão das atividades e do material didático (guia didático) o tutor mediador, tem a função de motivar os alunos, com o uso das ferramentas que a IE fornece, o tutor 
consegue verificar quem está fazendo as atividades e entrar em contato para saber o que está acontecendo e com isso dar um suporte e tornar o processo de aprendizagem da EaD mais humanizado, quebrando o gelo da tela do computador. Lembrando que o tutor mediador é responsável pela ponte entre o aluno e a instituição, entre o aluno e o professor e entre o aluno e o material/conhecimento. Cabendo o reconhecimento do tutor mediador como um professor.

Com relação à prática dos tutores mediadores e as questões de qualidade, percebe-se que a falta de preparação dos alunos emerge como um grande obstáculo percebido pelos tutores. Essa preparação engloba não somente as condições acadêmicas para ingressar em estudo de nível universitário, mas, talvez mais importante, a falta de compreensão daquilo que está envolvido no estudo a distância, em parte, em termos de um perfil que se adeque às disciplinas impostas por um modelo que tem o autoestudo e também em relação à informática. Uma das sugestões dos tutores mediadores é que seja criado um PRO-IN relacionado à informática. Essa sugestão foi passada para a coordenação e já estão providenciando esse nivelamento.

Logo, pode-se perceber que a tutoria proporciona experiências que permite o crescimento como profissional. A grande problemática que enfrentamos gera questionamento de valores, preconceitos e ações, e esses questionamentos encorajam uma reflexão continuada acerca dos caminhos da docência, de forma geral e na EaD.

Estamos caminhando para uma sociedade na qual o sistema educacional convencional, preso a modelos tradicionais, não tem mais espaço e dá lugares a sistemas flexíveis e diretamente ligados aos interesses individuais de quem quer aprender. Esse tipo de proposta educacional, que conta com a autonomia do aluno e exige do professor um constante aperfeiçoamento e muita criatividade, deve fazer parte das práticas tanto presenciais quanto a distância.

Ao longo da pesquisa pode-se perceber que os referenciais de qualidade são de extrema importância, o que vem a dar maior credibilidade e segurança tanto para a instituição, quando para os acadêmicos. Os objetivos propostos para a pesquisa foram contemplados e com isso foi possível chegar à conclusão de que o tutor tanto o presencial quando o mediador tem um papel fundamental na construção e desenvolvimento do 
processo pedagógico que envolve a educação a distância.

Com relação à segunda indagação/objetivo, percebemos a extrema importância da implantação de cursos na educação a distância à luz dos referenciais de qualidade, visto que eles abordam todos os critérios necessários para ofertar um bom curso aos acadêmicos, curso esse que deve contribuir para o crescimento crítico e intelectual do discente. No caso da instituição pesquisada, foi possível perceber que a mesma alicerça todos os departamentos da EaD embasa no referencial de qualidade, logo, ele deve ser considerado a base de toda EaD.

\section{REFERÊNCIAS}

ABRAEAD - Anuário Brasileiro Estatístico de Educação Aberta e a Distância. 3. ed. São Paulo: Instituto Monitor, 2008. Disponível em: www.abraead.com.br/anuario/anuario_2008.pdf. Acesso em: 03 mar. 2015.

ALMEIDA, Danuza Janne Ribeiro. e FIGUEIREDO, Lia. Camila dos Reis. A tutoria presencial. GO: ABED, 2010. Anais... $16^{\circ}$ Congresso Internacional de EaD - ABED, 2010. Disponível em: www.abed.org.br/ congresso2010/cd/152010190142.pdf. Acesso em: 17 mar. 2012.

ARREDONDO, Santiago Castillo. Formación / capacitación del profesorado para trabajar en EAD. Revista Educar, n. 21, 2003. Curitiba: Editora UFPR. Disponível em: http://ojs.c3sl.ufpr.br/ojs2/ index.php/educar/article/viewArticle/2120. Acesso em: 25 set. 2011.

AZEVEDO, Maria Antônia Ramos de. Os Saberes de Orientação dos Professores Formadores: Desafios para Ações Tutorais Emancipatórias. São Paulo: USP, 2009.

BALBÉ, Marta Maria Gonçalves. A Interlocução entre professor tutor e aluno na educação a distância. Educar, Curitiba, n. 21, p. 215-224. 2003. Editora UFPR.

BELLONI, Maria Luisa. Educação a Distância. Campinas: Autores Associados, 1994. 
. Educação a Distância. Campinas: Autores Associados, 2001.

. Educação a Distância. Campinas: Autores Associados, 2002.

. Educação a Distância. Campinas: Autores Associados, 2006.

BRASIL. Ministério da Educação. SEED. Referenciais de Qualidade para Educação a Distância. 2007. Disponível em: http://portal.mec. gov.br/seed/arquivos/pdf/referenciaisead.pdf. Acesso em: 17 fev. 2015.

\section{. Instituto Nacional de Estudos e Pesquisas Educacionais} Anísio Teixeira. Censo da educação superior 2011. Disponível em: portal.mec.gov.br/index.php?option=com_docman\&task. Acesso em: 17 fev. 2015.

. Portaria no 4059, de 10 de dezembro de 2004. Disponível em: http://portal.mec.gov.br/sesu/arquivos/pdf/nova/acs_portaria4059.pdf. Acesso em: 17 fev. 2015.

. Plano Nacional de Educação - Lei no 10.172. Ministério da Educação, 2001. CAMARA DOS DEPUTADOS. Proposta do projeto de lei 2435/11. 12 jan. 2012. Disponível em: http:// www2.camara.gov. br/agencia/noticias/EDUCACAO-E-CULTURA/207769-PROPOSTAREGULAMENTA-TUTORIA-EM-EDUCACAO-A-DISTANCIA.html. Acesso em: 17 fev. 2015.

. Lei de diretrizes e bases da educação nacional - LDBEN n. 9394 de 20 de dezembro de 1996. Estabelece as diretrizes e bases da educação nacional. Disponível em: http://www.planalto.gov.br/CCIVIL/ leis/L9394.htm. Acesso em: 17 fev. 2015.

. Ministério da Educação. Decreto Federal n ${ }^{\circ} .5 .622$, de 20.12.2005. Regulamenta o art. 80 da Lei ${ }^{\circ}$. 9.394, de 20 de dezembro de 1996, que estabelece as diretrizes e bases da educação nacional. Disponível em: http:/www.planalto.gov.br/ccivil_03/_Ato20042006/2005/Decreto/D5622.htm. Acesso em: 17 fev. 2015.

COSTA, Maria Inês. O que é ser tutor EaD?. Artigo. In: PORTAL 
DA ASSOCIAÇÃO NACIONAL DE TUTORES DA EDUCAÇÃO A DISTÂNCIA. Disponível em: http://www.anated.org.br/index. php?option $=$ com_content\&view $=$ article $\& i d=161$ :o-que-e-ser-tutor-ead \&catid=53:artigos\&Itemid=192. Acesso em: 10 mar. 2015

CUNHA, Maria Isabel da. Ensino como mediação da formação do professor universitário, In: MOROSINI, Marília (Org.). Professor do Ensino superior: identidade, docência e formação. Brasília: INEP, 1998.

EMERECIANO, Maria do Socorro; SOUSA, Carlos Alberto Lopes. \& FREITAS, Leda Gonçalves (2001) Ser presença como educador, professor e tutor. Colabora, Curitiba, v. 1, n. 1, p. 4-11, 2001.

FREIRE, Paulo. Pedagogia da Autonomia: saberes necessários à prática educativa. São Paulo: Paz e Terra, 1996.

GADOTTI, Moacir. Qualidade na Educação: uma nova abordagem. Fórum Estadual Extraordinário da Undime, São Paulo, 07 a 08 de dezembro de 2001. Disponível em: redesocial.unifreire.org/.../gadottiqualidade-educacao-forum-undim. Acesso em: 13 abr. 2015.

. A qualidade na educação. In: UNESCO, 2001. Disponível em: http://siteantigo.paulofreire.org/pub/Crpf/CrpfAcervo000158/ Legado_Artigos_Qualidade_Educacao_Moacir_Gadotti.pdf. Acesso em: 13 abr. 2015.

JULIATTO, Clemente Ivo. A Universidade em Busca da Excelência: um estudo sobre a qualidade da educação. 2. ed. Curitiba: Universitária Champagnat, 2005.

KENSKI, Vani Moreira. Educação e Tecnologias o Novo Ritmo da Informação. Campinas São Paulo, Papirus, 2010.

KANWAR, Asha; KOUL, Badri N. La Garantia de La Calidad y La Acreditacíon de La Educación Superior a Distancia en La Commnwealth. In: La Educación Superior en el Mundo 2007: Acreditación para la Garantía de la Calidad: ¿ Qué está en Juego? 
Barcelona: Ediciones Mundi-Prensa, 2006. Anais GUNI - 2006.

LEMGRUBER, Marcio Silveira. Educação a Distância: para além dos caixas eletrônicos. Pernambuco. In: Anais do $2^{\circ}$ Simpósio Hipertexto e Tecnologias na Educação, 2008. Disponível em: http:// portal.mec.gov.br/arquivos/conferencia/documentos/marcio_lemgruber. pdf. Acesso em: 18 abr. 2015.

MASETTO, Marcos. Mediação pedagógica e o uso da tecnologia. In: MORAN, José Manuel; MASETTO, Marcos; BEHRENS, Maria Aparecida. Novas tecnologias e mediação pedagógica. Campinas, SP: Papirus, 2000.

MARTINS, Onilza Borges (2003). Teoria e prática tutorial em educação a Distância. Educar, Curitiba, n. 21. UFPR, 2003.

MORAN, José. O que é educação a distância. 2002. Disponível em: http://www.eca.usp.br/prof/moran/textosead.htm. Acesso em 19 fev. 2015.

MUNHOZ, Antônio Siemsen. (2003) A Educação a Distância em busca do tutor ideal. Colabora, Revista Digital da CVA - RICESU, v. 2, n. 5, p. XX-Xx, 20??

NEDER, Maria Lucia Cavalli. A Orientação Acadêmica na Educação a Distância: a perspectiva de (re) significação do processo educacional. In: PRETI, O. (Org.). Educação a Distância: construindo significados. Brasília: Plano, 2000.

NETTO, Carla; GIRAFFA, Lucia; FARIA, Elaine. Graduações a distância e o desafio da qualidade. Porto Alegre: EDIPUCRS, 2010.

PEDROSA, Stella Maria Peixoto de Azevedo. (2003). A educação a distância na formação continuada do professor. Educar, Curitiba, n. 21. UFPR, 2003.

PETERS, Otto. A educação a distância em transição. Tendências e desafios. (L. F. de S. Mendes, Trad.). São Leopoldo: Unisinos, 2004. 
. Didática do ensino a distância, Experiências e estágio da discussão numa visão internacional. (I. Kayser, Trad.). São Leopoldo, Unisinos, 2006.

PRETI, Oreste. Educação a distância e Globalização: Desafios e tendências. Em: Educação a distância: Construindo significados. Oreste Petri (Org.). Cuiabá: NEAD/IE - UFMT; Brasilia: Plano, 2000.

SILVA, Ana de Paula. Avaliação de uma disciplina a distância de graduação ofertada pela ead. Dissertação de mestrado. Universidade de Brasília, Brasília. 2010.

SCHLOSSER, Lakatos. A atuação dos tutores nos cursos de educação a distância. 2010. Colabor@- Revista Digital da CVA - Ricesu, v. 6, n. 22,2012

TAROUCO. Liane. Educação a Distância. Disponível em http://www. sead.ufpa.br/v2/home/index.php?pag=entrevistaLiane. Acesso em: 22 fev. 2015.

Recebido em: 18/09/2019

Aprovado em: 14/07/2020 